\title{
THE IRON I/IIA TRANSITION IN THE LEVANT: A REPLY TO MAZAR AND BRONK RAMSEY AND A NEW PERSPECTIVE
}

\author{
Israel Finkelstein \\ Department of Archaeology and Ancient Near Eastern Civilizations, Tel Aviv University, Israel. Email: fink2@post.tau.ac.il. \\ Eli Piasetzky \\ School of Physics and Astronomy, Tel Aviv University, Israel.
}

\begin{abstract}
Mazar and Bronk Ramsey (2008) recently proposed that the Iron I/IIA transition in the Levant took place during the first half of the 10th century. In the first part of this article, we challenge their method and conclusions. We argue against the inclusion of charcoal in their model, which could lead to an "old wood effect." We also argue that in dealing with a transition date, all available data must be taken into consideration. In the second part of the article, we propose Bayesian Model I for the Iron I/IIA transition, which is based on 2 sets of data - for the periods immediately before and after this transition. Our model, along with the other 11 published Bayesian models for this transition that used only short-lived samples, agrees with the Low Chronology system for the Iron Age strata in the Levant and negates all other proposals, including Mazar's Modified Conventional Chronology. The Iron I/IIA transition occurred during the second half of the 10th century. In the third part of the article, we present a new insight on the Iron I/IIA transition. We propose that the late Iron I cities came to an end in a gradual process and interpret this proposal with Bayesian Model II.
\end{abstract}

Mazar and Bronk Ramsey (2008) recently challenged Sharon et al. (2007; also Boaretto et al. 2005) and us (e.g. Finkelstein and Piasetzky 2003, 2007a,b) regarding the date of transition from the Iron I to the Iron IIA in the Levant. While we and Sharon et al. placed this transition in the second half of the 10th century BCE, Mazar and Bronk Ramsey positioned it "during the first half of the 10th century BCE" and argued that "the second half of the 10th century BCE should be included in the Iron IIA" (Mazar and Bronk Ramsey 2008:178). We discuss some problems in the methodology of Mazar and Bronk Ramsey that may have influenced their results. In particular, we discuss 1) the exclusion of data; 2) the inclusion of data (charcoal samples); and 3) show that even according to Mazar and Bronk Ramsey, excluding these samples position the late Iron I/IIA transition in the late 10th century. Finally, we present our own 2 Bayesian models for the Iron I/IIA transition.

\section{METHODS}

In dealing with a dating problem that involves a large number of radiocarbon results, and a debate that focuses on a time period that is brief, it is essential to engage a rigorous method for the inclusion and exclusion of data, since non-systematic selection of data can lead to different interpretations. In our previous studies on Iron Age chronology (e.g. Finkelstein and Piasetzky 2003, 2006), we worked with a clear set of criteria for accepting or rejecting measurements and with a simple and consistent procedure for interpreting the data:

- Due to the risk of the "old wood effect," only short-lived samples were included;

- All available readings from loci safely assigned stratigraphically and well classified from the point of view of ceramic typology were incorporated;

- Results of all laboratories were included;

- The uncalibrated dates corresponding to a given stratum were checked for consistency by fitting to a constant. Only readings that are different by more than 5 standard deviations from the average of the other measurements in their group were excluded as outliers.

Abiding by these rules guards against describing results as "too high" or "too low" (Mazar and Bronk Ramsey 2008:171 for Hazor), labels that may hint at preconceived theories. It is difficult to identify such a method in Mazar and Bronk Ramsey's paper. Beyond their mathematical procedure, which we accept as legitimate (though not the only possibility), we disagree with some of their decisions of what to exclude from, and what to include in, their calculations. 


\section{UNJUSTIFIED EXCLUSION OF DATA}

When one wishes to establish the date of transition between 2 periods, every piece of relevant information available must be used in the model chosen for the investigation. Mazar and Bronk Ramsey are aware of this when they write that: "... a more comprehensive study that will include all the available dates from this period (including all the Tel Rehov dates), may change the picture" (2008:179). Below, we list data excluded by Mazar and Bronk Ramsey from their Bayesian model (of 3 phases: the Late Bronze and the span of the Iron I, the late Iron I, and the Iron IIA), which in our opinion, needs better justification. ${ }^{1}$

A. Large sets of results from Tel Rehov and Tel Dor were omitted "since both were discussed in detail in the publications mentioned above" (Mazar and Bronk Ramsey 2008:161). For Tel Rehov, doing this left them with the few measurements for the early Iron IIA Stratum VI but without the many late Iron IIA readings from Strata V and IV. Obviously, this data selection may lead to a bias toward higher results. Had their article dealt with publication of new data, such a decision would have been understandable. But this is not the case here; almost all data in their article had already been published elsewhere. Similarly, there is no reason to exclude the measurements from the layers of the bichrome phase of Iron I Tel Miqne (Sharon et al. 2007:28; see Finkelstein and Piasetzky 2007a,b for their significance) only because they are not mentioned in Boaretto et al.'s first article (2005; Mazar and Bronk Ramsey 2008:161).

B. Twelve dates from the late Iron I Stratum IV at Tel Hadar were omitted because we supplied only their average date. Yet, these results are easy to obtain, and an average is as indicative as the detailed set of determinations.

C. Twelve readings from the Iron I site of el-Ahwat were excluded because the pottery of this site has not yet been published. This is inconsistent with the rest of the article. The pottery of Hebron and Bethsaida still has not been published (Mazar and Bronk Ramsey 2008:171), yet Mazar and Bronk Ramsey include samples from these sites.

D. We see no reason to exclude the important determinations for the bichrome, Iron I phase at Beth-shemesh (Finkelstein and Piasetzky 2007b; Sharon et al. 2007:27) only because a sample from a later phase at this site comes from an insecure context (Mazar and Bronk Ramsey 2008: 161).

E. We do not see the logic of including results from only 1 of the 3 Tell el-Hammah destruction layers. Why exclude the late Iron I samples as coming "from a small probe" and include other samples from similarly small probes? And why accept the determinations for the lower Iron IIA layer and exclude the readings for the upper Iron IIA destruction?

F. Mazar and Bronk Ramsey exclude some of the Hazor determinations as being "too low," though there is no statistical—or archaeological—reason to do so.

\section{PROBLEMATIC INCLUSION OF DATA: CHARCOAL SAMPLES INTRODUCE THE "OLD WOOD EFFECT"}

Measurements that originate from charcoal samples may introduce the well-known "old wood effect" (Schiffer 1986; Sharon et al. 2007:5-6 for the case discussed here). This is especially so in multiperiod sites such as the mounds of the ancient Near East, where the inhabitants may have routinely recycled used timber for construction. In certain cases, a quick glance at a set of determinations that originate from charcoal/wood samples is sufficient for concluding that the samples repre-

${ }^{1}$ We use all determinations in this list that belong to the late Iron I and the early Iron IIA - the 2 phases that we have chosen for our Bayesian models. 
sent old wood. However, at sites characterized by dense stratigraphy, the reused wood may originate from a previous layer close in date to the one under investigation, which, taking into consideration the uncertainty in the results, is impossible to detect. In addition, in the case of long-lived tree species such as oak and juniper, the sample measured may derive from the inner rings of the tree, which may be significantly older than the date when the tree was felled. Therefore, ${ }^{14} \mathrm{C}$ dates of charcoal and wood can only provide a terminus post quem for the stratum where they were found.

Mazar and Bronk Ramsey include charcoal determination in their calculations and the consequence is indeed a bias toward older dates. Figure 1, which presents the data in Mazar and Bronk Ramsey's Table 1 (end of Late Bronze and Iron I; 2008:162) demonstrates this problem. The charcoal excluded by Mazar and Bronk Ramsey as "old wood" are the last 4 on the right. The figure makes it clear that even the other charcoal measurements, which were included in their calculations, are significantly (and systematically) older than the short-lived measurements. Table 1 presents the "old wood effect" for both the Late Bronze and the Iron I.

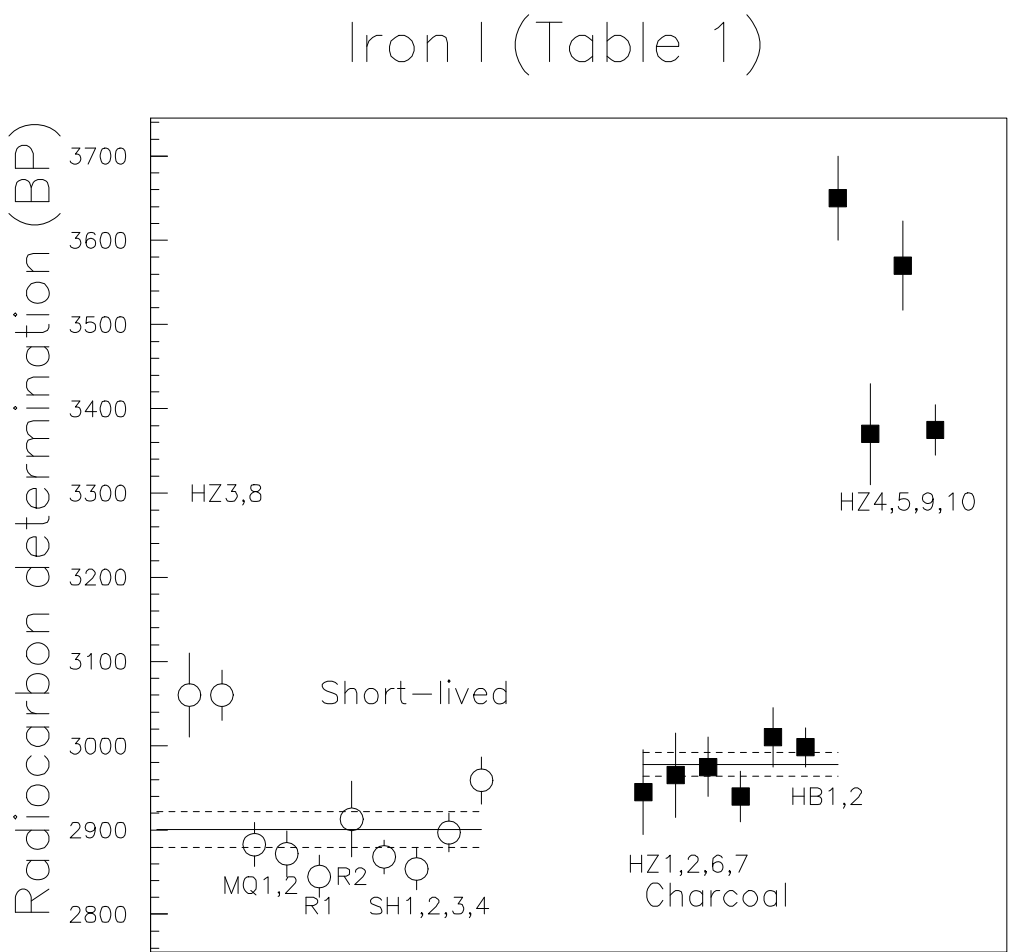

Figure 1 Samples used in Table 1 of Mazar and Bronk Ramsey (2008:162), divided into short-lived (empty circles) and charcoal (black squares). The charcoal results are consistently and meaningfully earlier than the short-lived results.

Table 1 Mazar and Bronk Ramsey's Table 1, with and without charcoal.

\begin{tabular}{lll}
\hline & Iron I & Late Bronze \\
\hline Short-lived samples only & $2901 \pm 21$ & $2914 \pm 15$ \\
Charcoal only & $2978 \pm 14^{\mathrm{a}}$ & $2989 \pm 16$ \\
Difference & $77 \pm 25(3.1 \sigma)$ & $75 \pm 20(3.8 \sigma)$ \\
\hline
\end{tabular}

${ }^{a}$ Without the 4 outliers as defined by Mazar and Bronk Ramsey. 
In the case of the Iron I, this translates into calibrated dates (68\%) of 1126-1045 BCE for the shortlived results and 1262-1134 BCE for the charcoal results, a meaningful difference; the two do not even overlap.

The case of Hazor provides another example of what we discussed earlier. Mazar and Bronk Ramsey include in their analysis 10 determinations from Strata XII-XI at the site. These layers are dated by all authorities to the Iron I, and not to a very early phase of this period (e.g. Mazar 1981:35; Finkelstein 1988:100-1). Two of the samples provide dates in the early 2nd millennium BCE. The other dates too do not conform with any dating paradigm of the Iron I pottery at Hazor. The samples (most of them charcoal, but 2 are short-lived) were retrieved from Iron I pits that were dug into the thick destruction layer of Late Bronze Hazor. They probably originated from the previous stratum (see discussion in Sharon et al. 2007:5-6). The date of destruction of Late Bronze Hazor is earlier than the terminal Late Bronze (Beck and Kochavi 1985); therefore, these samples should not have been included, even according to Mazar and Bronk Ramsey's method of mixing terminal Late Bronze and Iron I readings in 1 block of results.

The summary figures in Mazar and Bronk Ramsey (2008:173) perfectly demonstrate what has been said above. Their Model B, which includes "two phases with other additional data," produces 2 results for the Iron I/IIA transition (68\% probability): 944-927 and 954-934 BCE (the latter after removing outliers). Not surprisingly, the same model excluding the charcoal provides a later date: 940-917 BCE (their graph B3). The same holds true for their Model C (2 phases with an overlapping late Iron I phase): 961-947 and 961-942 BCE with the charcoal samples; 948-919 BCE without charcoal (their graph C3). In other words, excluding the charcoal alone-without treating the other problematic exclusions discussed above - is enough to convert Mazar and Bronk Ramsey results to the Low Chronology for the Iron Age strata in the Levant, according to which the transition from the Iron I to the Iron IIA took place in the second half of the 10th century BCE.

\section{ALTERNATIVE BAYESIAN MODELS}

\section{Model I}

In Model I, we assume, with Mazar and Bronk Ramsey, that the Iron I/IIA transition was a shortterm event. In order to determine the transition date, Mazar and Bronk Ramsey (2008) use 3 sets of data: 1) for the end of the Late Bronze and "the span of the Iron I" (that is, the Iron I, not including the late Iron I); 2) for the late Iron I; and 3) for the "span of the Iron IIA" (that is, both the early and late Iron IIA). We think that 2 sets of data suffice - those that come from strata dated to the phase immediately before the transition and those that come immediately after it (Figure 2; Tables 2-3; for a somewhat similar idea see Sharon et al. 2007): A) the late Iron I (for this ceramic phase see Arie 2006); B) the early phase of the Iron IIA (for this ceramic phase see Herzog and Singer-Avitz 2004, 2006). These 2 sets of data (Figure 2) should give a more pinpointed and less biased result, as they leave out determinations for phases much earlier and much later than the transition under discussion.

Our model is based on our standard rules: We do not include charcoal, and we do not a priori exclude a sample as an outlier, unless it is more than $5 \sigma$ from the error-weighted average (see above) for the given stratum. If possible, we prefer to use samples from destruction layers; this reduces the risk of contamination, shifting of the original seeds/olive pits, or a mistake in the stratigraphic affiliation. 


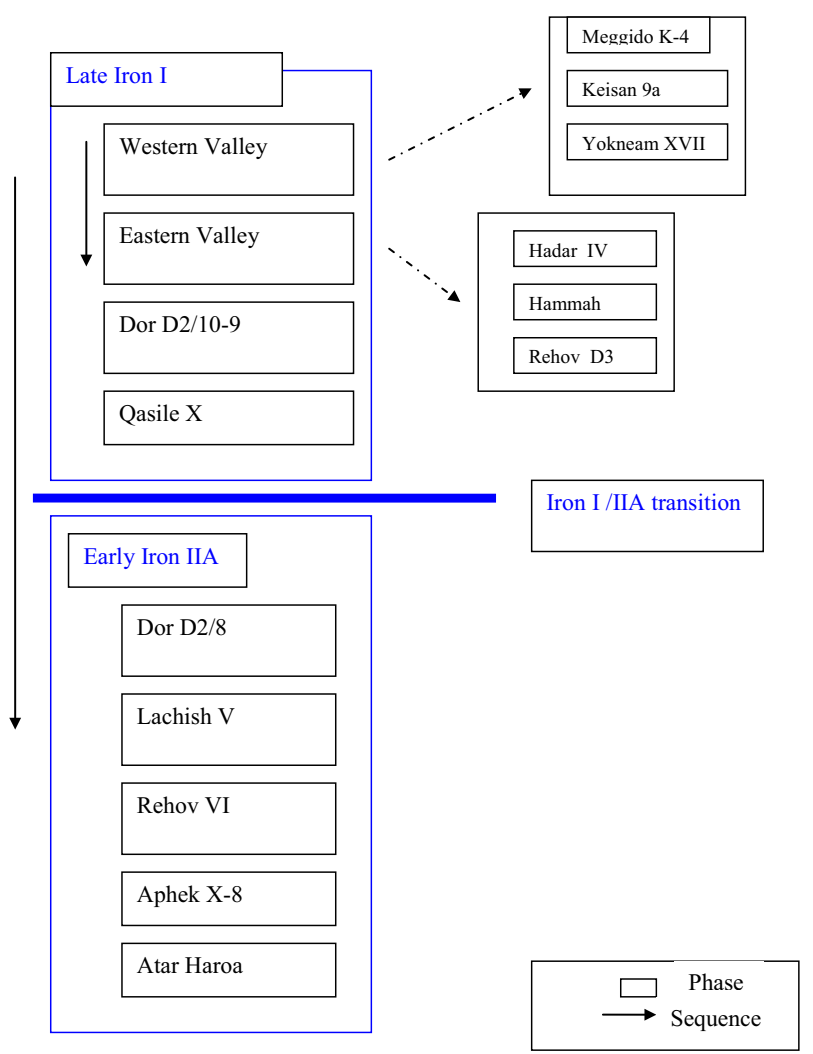

Figure 2 The sets of data (early to late) used for Bayesian Model I of the Iron I/IIA transition.

For the Late Iron I, we have included 8 sites/strata: 3 in the western Jezreel Valley (Megiddo, Tel Keisan, and Tel Yokneam); 3 in the eastern Jezreel Valley (Tel Hadar, Tell el-Hammah, and Tel Rehov); and 2 on the coastal plain (Tel Dor and Tel Qasile):

- Megiddo. Samples were taken from the thick destruction layer of Level K-4 (= Stratum VIA of the University of Chicago excavations; Gadot et al. 2006).

- Tel Keisan. Samples were retrieved from Stratum 9a, which was destroyed in heavy conflagration (Humbert 1980:20).

- Tel Yokneam. The division of Stratum XVII into 2 phases (b and a) is based on minor architectural alterations (Zarzecki-Peleg 2005:17-8); it is reasonable to assume that the charred olive pits originated from the destruction that sealed Stratum XVII (see pictures in Zarzecki-Peleg 2005:22-32).

- Tel Hadar. Samples were taken from a large quantity of charred grain found sealed under a thick layer of destruction debris of Stratum IV (Kochavi 1998:470-1).

- Tel Hammah. Samples were collected from the destruction layer of the late Iron I stratum (Cahill 2006).

- Tel Rehov. Samples were taken from a series of pits assigned to Stratum D-3-the last Iron I layer at the site (Mazar et al. 2005:208; see comments regarding the stratigraphy and method of data selection for ${ }^{14} \mathrm{C}$ analysis in Finkelstein and Piasetzky 2003, 2006). No destruction has been reported. 


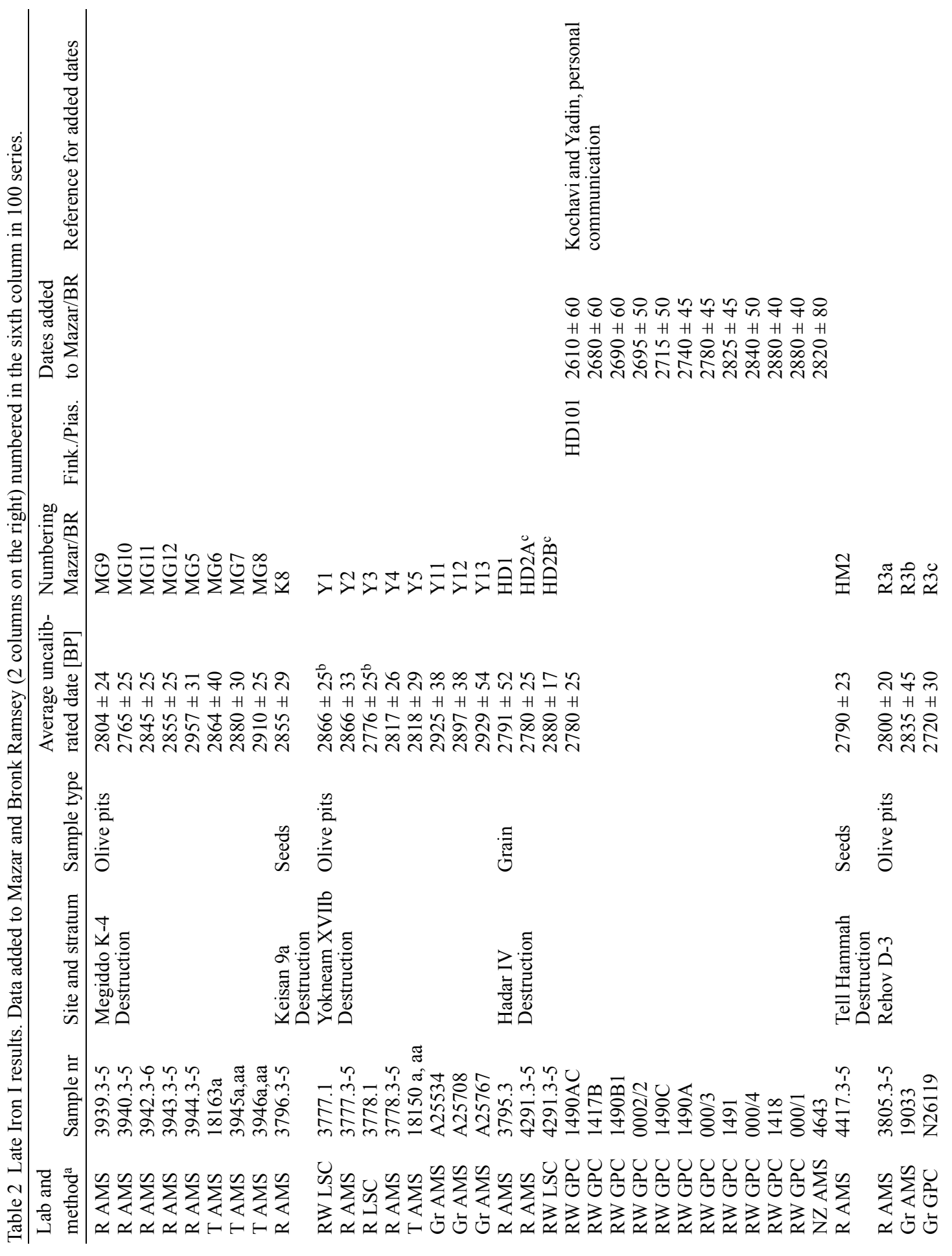




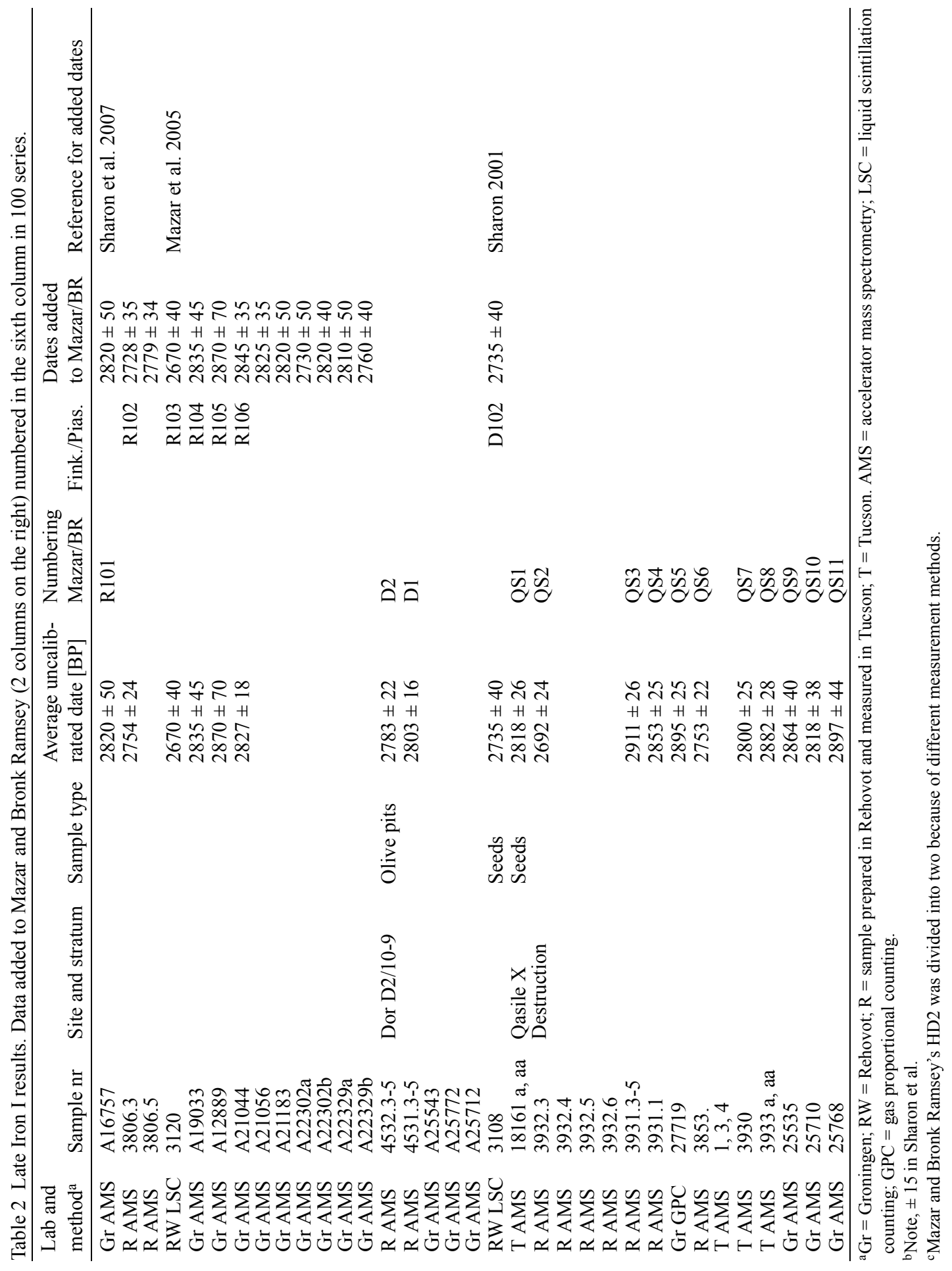


- Tel Dor. Area D-2 Stratum 10-9; the samples came from a building that was abandoned rather than destroyed (Gilboa and Sharon 2003:33-4).

- Tel Qasile. Samples were taken from the thick destruction layer of Stratum X (Mazar 1980:33, 46; 1985:127).

For the early Iron IIA, we include 4 sites: 1 in the Jezreel Valley (Tel Rehov); 2 on the coastal plain (Tel Dor and Tel Aphek); and 2 in the south (Tel Lachish and Atar Haroa): ${ }^{2}$

- Tel Rehov. The sample comes from Stratum VI in Area C - the earliest Iron IIA layer at the site (Mazar et al. 2005:217-20).

- Tel Dor. Samples were retrieved from Stratum D2/8c, which has been equated with the early Iron IIA Stratum VB at Megiddo (Gilboa and Sharon 2003:55).

- Tel Aphek. Samples were taken from carbonized grain seeds found in storage jars in pits of Stratum X-8 (for the stratum and its pottery see Gadot 2003).

- Lachish. The single sample was retrieved from Level V-the classical early Iron IIA layer in the Shephelah (Zimhoni 1997; Mazar and Panitz-Cohen 2001:274-5; Herzog and Singer-Avitz 2004).

- Atar Haroa. Fifteen samples were retrieved from this site in the Negev Highlands (ShahackGross and Finkelstein 2008). The affiliation of this site with the early Iron IIA is agreed by all authorities (Herzog and Singer-Avitz 2004; Mazar 2005:24). Only an average date for the 15 samples is given here; the full results are published in Boaretto et al. (2010).

Altogether, the database includes 107 and 32 measurements for the late Iron I and early Iron IIA, respectively; they make 45 late Iron I and 8 early Iron IIA points in the "average uncalibrated date" columns. Similar to Mazar and Bronk Ramsey (2008), the averages are weighted by the size of the laboratory standard error. In some cases, there were small, insignificant differences between our average dates and Mazar and Bronk Ramsey's; in those cases we adopted their values. The data were assembled from 13 strata at 11 sites; the samples were measured in 4 laboratories using 3 methods.

We performed Bayesian analysis using the OxCal program (Bronk Ramsey 1995, 2001; the OxCal specifications of the model are available in the online version of Mazar and Bronk Ramsey 2008). The Bayesian model for all the data in Tables 2-3 (Model I) puts the Iron I/IIA transition in 894-871 BCE (68\% range) and 903-859 BCE (95\% range) (Figure 3). But the agreement between the data and the model is poor (31\%). The system signals 5 results that are especially poorly consistent with the full model. ${ }^{3}$ These are HD2B and MG5 (too high) and R103, A1, and QS2 (too low). By removing them (for a similar process see Boaretto et al. 2005; Mazar and Bronk Ramsey 2008), one can improve the overall agreement to $82 \%$ (Figure 4). This process results in a transition date of 915 $898 \mathrm{BCE}(68 \%$ range), or $927-879 \mathrm{BCE}$ (95\% range). The robustness of this model is noteworthy. First, extending it to include the early/middle Iron I and the late Iron IIA, results in a similar transition date. Second, without removing any data from the model the date of the transition is even lower than the final result. Third, removing more points than we propose increases the agreement between the data and the model, but does not change the result. All this means that reasonable changes in the database would not result in an Iron I/IIA transition in the first half of the 10th century BCE.

${ }^{2}$ We have not included Mazar and Bronk Ramsey's R4, R5, R5a, and R8 for Rehov VI, as their stratigraphic affiliation is not secure (Mazar et al. 2005:201; Mazar and Bronk Ramsey 2008:170; including them one gets an average uncalibrated date of $2773 \pm 10$ for Tel Rehov VI—not a very different result). Samples BD1 and BD2 also come from insecure provenance (Sharon et al. 2007:7).

${ }^{3}$ The individual agreement index calculated by OxCal, checks how well the prior model agrees with each individual datum. Following Mazar and Ramsey (2008), we carried out an interactive procedure where we started with the prior model and improved it by removing the few measurements that do not agree with it. 
Table 3 Early Iron IIA results. Data added to Mazar and Bronk Ramsey ( 2 columns on the right) numbered in the sixth column in 100 series.

\begin{tabular}{|c|c|c|c|c|c|c|c|c|}
\hline $\begin{array}{l}\text { Lab and } \\
\text { method }^{\mathrm{a}}\end{array}$ & $\begin{array}{l}\text { Sample } \\
\mathrm{nr}\end{array}$ & $\begin{array}{l}\text { Site and } \\
\text { stratum }\end{array}$ & $\begin{array}{l}\text { Sample } \\
\text { type }\end{array}$ & $\begin{array}{l}\text { Average } \\
\text { uncalib. } \\
\text { date }[\mathrm{BP}]\end{array}$ & $\begin{array}{l}\text { Number } \\
\text { Mazar/ } \\
\text { BR }\end{array}$ & $\begin{array}{l}\text { ring } \\
\text { Fink./ } \\
\text { Pias. }\end{array}$ & $\begin{array}{l}\text { Dates } \\
\text { added to } \\
\text { Mazar/BR }\end{array}$ & $\begin{array}{l}\text { Reference for } \\
\text { added dates }\end{array}$ \\
\hline RW LSC & 2960 & Dor D2/8c & Olive pits & $2710 \pm 20$ & & D101 & & $\begin{array}{l}\text { Gilboa and } \\
\text { Sharon } 2003\end{array}$ \\
\hline $\begin{array}{l}\text { R AMS } \\
\text { Gr AMS }\end{array}$ & $\begin{array}{l}4540.3-5 \\
\text { A25544 }\end{array}$ & & & $2757 \pm 18$ & D3 & & & \\
\hline Gr AMS & A 25714 & & & & & & & \\
\hline Gr AMS & A25787 & & & & & & & \\
\hline R AMS & $4541.3-5$ & & & $2764 \pm 22$ & D4 & & & \\
\hline R AMS & $4542.3-5$ & & & $2779 \pm 24$ & D5 & & & \\
\hline RW LSC & 3159 & Lachish V & & $2775 \pm 55$ & & L101 & & $\begin{array}{l}\text { Carmi and } \\
\text { Ussishkin } 2004\end{array}$ \\
\hline Gr GPC & 27366 & Rehov VI & Seeds & $2761 \pm 14^{b}$ & & R107 & & $\begin{array}{l}\text { Mazar et al. } \\
2005\end{array}$ \\
\hline R AMS & 4511.3 & Aphek X-8 & Seeds & $2667 \pm 20$ & A1 & & & \\
\hline R AMS & 4511.4 & & & & & & & \\
\hline R AMS & 4511.5 & & & & & & & \\
\hline R AMS & & Haroa & $\begin{array}{l}\text { Date pits, } \\
\text { barley, grape }\end{array}$ & $2721 \pm 13$ & & HA101 & & $\begin{array}{l}\text { Boaretto et al. } \\
2010\end{array}$ \\
\hline
\end{tabular}

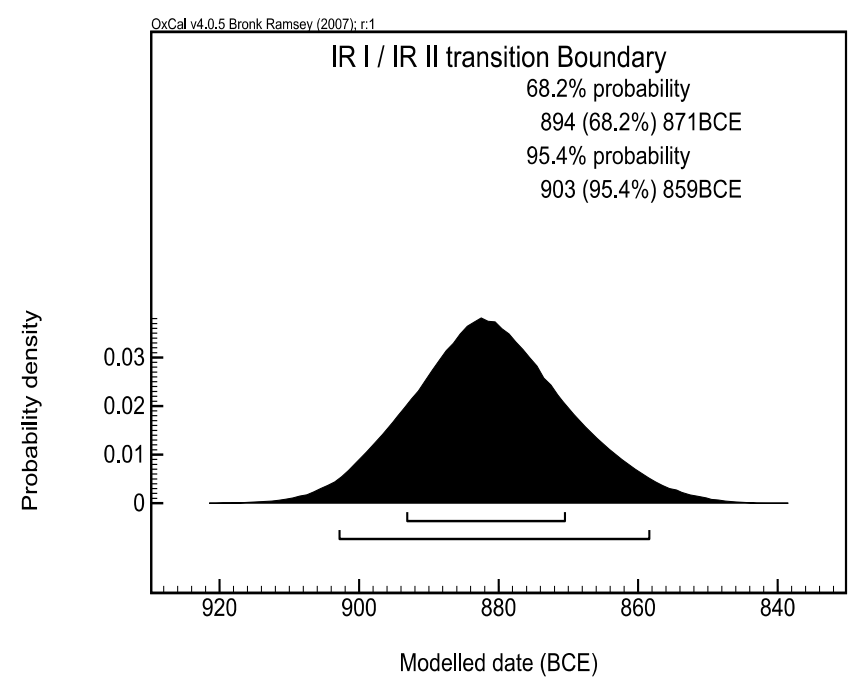

Figure 3 The Iron I/IIA transition according to Model I, including all data in Tables $2-3$ ( $31 \%$ overall agreement).

Table 4 presents the results of all 12 published Bayesian models for the Iron I/IIA transition that use only short-lived samples. Eleven put this transition in the second half of the 10th century and one somewhat later. These results are in line with the Low Chronology (Finkelstein 1996; Finkelstein and Piasetzky 2003; Sharon et al. 2007), clearly negating all other theories - the traditional dating of this transition in 1000 BCE; Mazar's Modified Conventional Chronology, which puts it in $\sim 980$ BCE (2005); and even Herzog and Singer-Avitz's proposal $(2004,2006)$ to date the transition to the mid-10th century. 


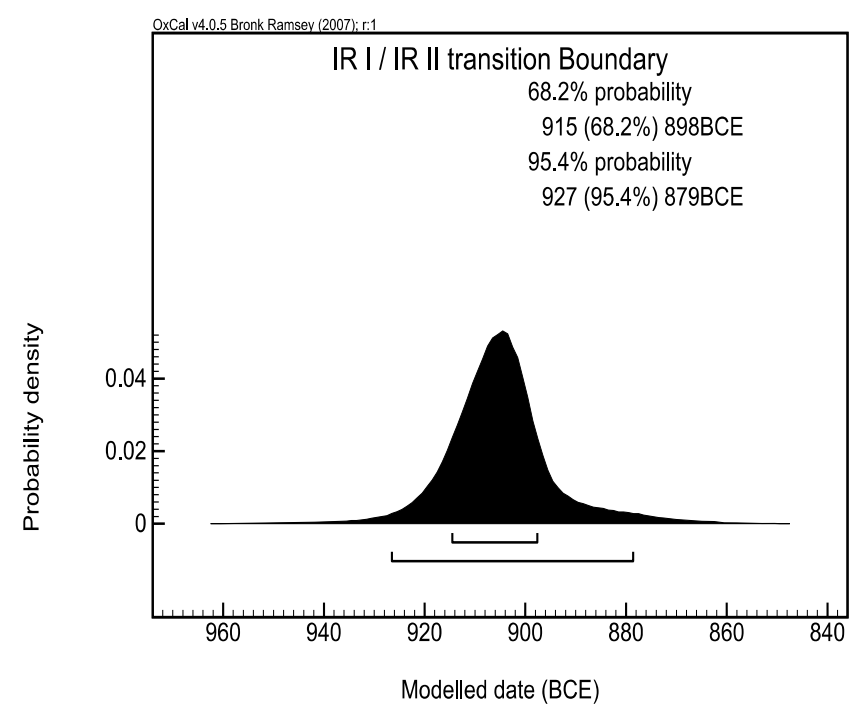

Figure 4 The Iron I/IIA transition in Model I after excluding points of disagreement between the set of data and the model ( $82 \%$ overall agreement).

Table 4 All available Bayesian models for the Iron I/IIA transition using only short-lived samples.

\begin{tabular}{lll}
\hline Model & Dates [68\% range] & Reference \\
\hline Focused/combined & $925-885$ & Sharon et al. 2007 \\
Focused/uncombined & $900-870$ & \\
Focused/cautious & $935-895$ & \\
Composite/combined & $925-895$ & \\
Composite/uncombined & $915-900$ & \\
Composite/cautious & $925-900$ & \\
Coarse/combined & $955-925$ & \\
Coarse/uncombined & $930-910$ & Mazar and Bronk Ramsey 2008 \\
Coarse/cautious & $940-905$ & \\
Model B3 & $940-917$ & This work \\
Model C3 & $948-919$ & \\
Model I in this work & $915-898$ & \\
\hline
\end{tabular}

\section{Model II}

All models presented in Table 4 are based on the assumption that the Iron I/IIA transition was a relatively short-term event. In what follows, we present Bayesian Model II, which assumes a gradual deterioration of the Iron I cities (and thus, ceramic tradition). It is based on our recent observation that the uncalibrated dates of late Iron I destruction layers in 5 sites in the Jezreel Valley in northern Israel (and the date of a sixth site with no destruction layer) assemble into 2 groups, which show geographical logic (Finkelstein and Piasetzky 2007b; Figure 5):

1. The western Jezreel Valley-Acco plain sites (Megiddo K-4, Yokneam XVII, and Keisan 9aall destruction layers), with an error-weighted average uncalibrated destruction date of $2852 \pm$ $13 \mathrm{BP}$.

2. The eastern Jezreel Valley - Sea of Galilee sites (Destructions layers at Tel Hammah and Hadar IV; pits at Rehov D-3), with an error-weighted average uncalibrated date of $2794 \pm 10 \mathrm{BP}$. 


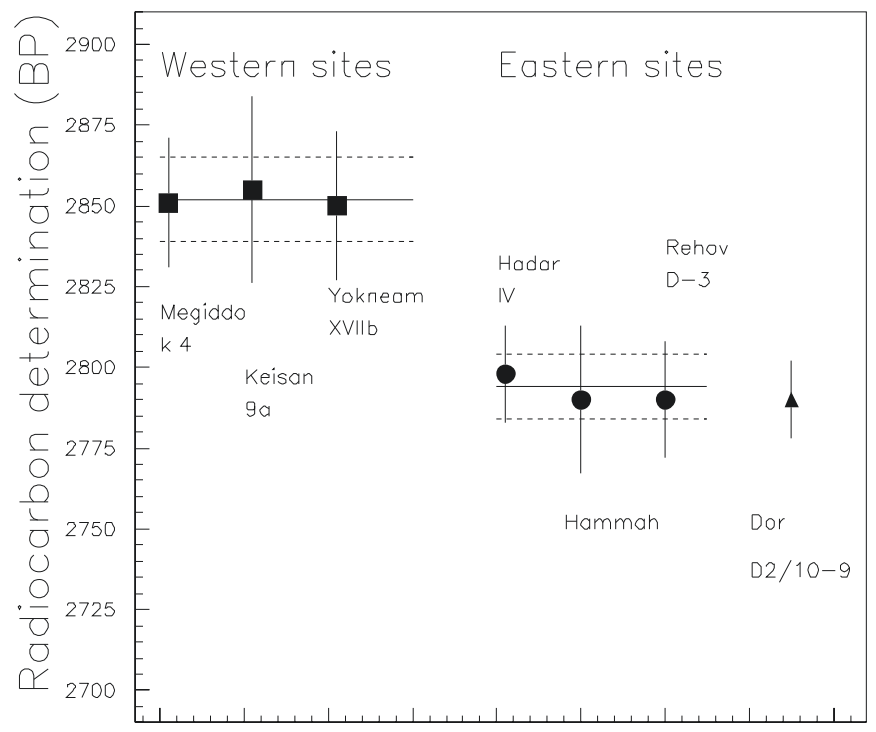

Figure 5 The average uncalibrated date for late Iron I site in the Jezreel Valley. The solid lines mark the error-weighted average for each group, west and east. The dashed lines are the $1-\sigma$ limits of the latter average.

Averaging uncalibrated results calls for an explanation. In the case of a destruction layer, samples found on the floors can be taken as representing a single event - the final hours of the settlement. It is therefore legitimate to average their results (in order to reduce the uncertainty of the results). Even if the original products had accumulated in the few years before the destruction, the difference in their age determination would be smaller than the uncertainty in their measurement. This is especially true in our case, in which the samples comprise of grain seeds and olive pits; they could not have been stored for more than 1 or $2 \mathrm{yr}$ at the most. Even if stored in Year X, in Year X+1 the products would either be consumed (in the case of drought) or consumed and replaced by fresh crops (in the case of good yield). ${ }^{4}$ Compared to the uncertainty in the measurements, the possible year or two in which the grain and olives were stored prior to the destruction event is negligible. ${ }^{5}$ It is also safe to assume that in such a case the fluctuations in the atmospheric concentration of ${ }^{14} \mathrm{C}$ during the very short time are negligible.

The 2 groups described above are separated by 58 uncalibrated years, that is, $3.5 \sigma$. The probability that they represent a single date is very low. Most likely, these data indicate 2 events, or better 2 clusters of events. In other words, the demise of the late Iron I culture in northern Israel was a gradual one.

Model II (Figure 6) describes this process (adding late Iron I strata along the coastal plain of Israel, one of which ended in a major conflagration). This model evaluates the dates for the gradual end of the late Iron I sites as well as the date for the beginning of the Iron IIA.

\footnotetext{
${ }^{4}$ We wish to thank Food Scientist Dr Baruch Rosen for providing us with this information.

${ }^{5}$ As an example: In the case of dating destruction layers, if the uncertainty in the measurement is $20 \mathrm{yr}$, then an additional uncertainty of 1 or $2 \mathrm{yr}$ (because of storage) would change the uncertainty of the determination by less than a year.
} 


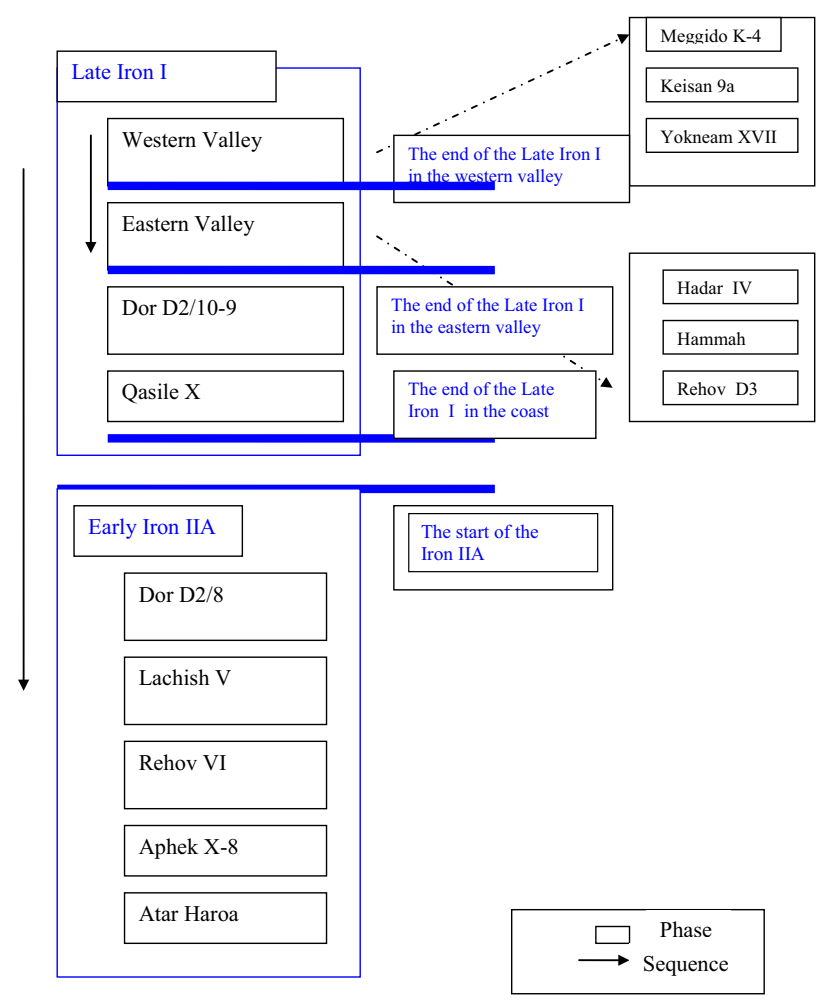

Figure 6 Bayesian Model II (early-to-late), assuming a gradual demise of the late Iron I cities.

Following the procedure undertaken by Mazar and Bronk Ramsey (2008; explained in the discussion of Model I above), we have removed 6 data points that are not consistent with the model. These are the same 5 items removed from Model I plus Item R3C. This procedure resulted in an overall $64 \%$ agreement between the data and the model. To check the robustness of the results, we removed the next 2 data points, which are in poor agreement with the model. The agreement increased to $95 \%$, but the results remained practically the same.

Table 5 and Figure 7 present the results of Model II, compared to the results of Model I and to the straightforward calibrated (non-Bayesian) determinations obtained from the error-weighted average of the uncalibrated dates.

Table 5 Summary table for Model II, compared to the results of Model I and a simple, non-Bayesian determination; all dates are $\mathrm{BCE}, 68 \%$ range. $^{\mathrm{a}}$

\begin{tabular}{|c|c|c|c|}
\hline Ceramic phase & Model II & Model I & Non-Bayesian determination \\
\hline 1. End of Iron I in the western Jezreel Valley & $1000-969$ & & $1050-996$ \\
\hline Transition between 1 and 2 & & $976-955$ & \\
\hline 2. End of Iron I in the eastern Jezreel Valley & $970-920$ & & $974-915$ \\
\hline 3. End of Iron I including sites along the coast & $940-894$ & & \\
\hline Iron I/IIA transition & & $915-898$ & \\
\hline Beginning of the Iron IIA & $921-863$ & & \\
\hline
\end{tabular}

${ }^{a}$ The $95 \%$ range results are as follows: for the end of the late Iron I in the western Jezreel Valley, 1008-948 BCE; for the end of the late Iron I in the eastern Jezreel Valley, 975-908 BCE; for the end of the late Iron I including the coastal plain, 961$881 \mathrm{BCE}$; for the beginning of the Iron IIA, 932-852 BCE. 


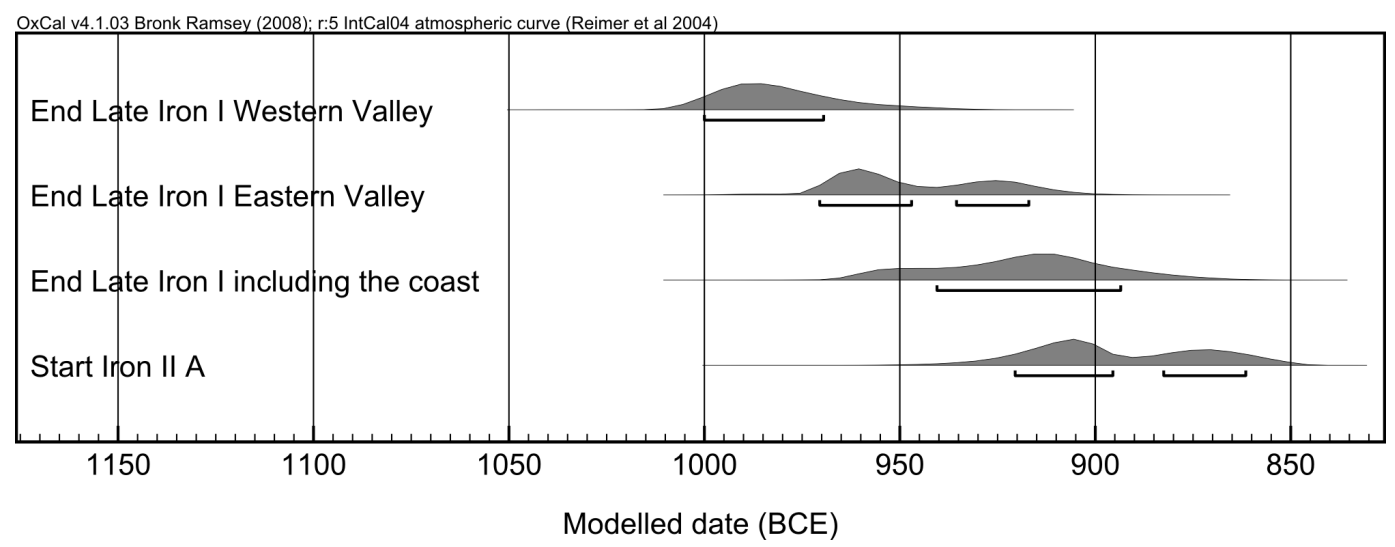

Figure 7 Results of Model II, showing the gradual late Iron I deterioration during the 10th century and the beginning of the Iron IIA in the second half of the 10th century.

The results of Models II and I are consistent with each other, as well as with the non-Bayesian determinations (third column); the small differences between them reflect the different assumptions behind the models and the uncertainties in them.

\section{CONCLUSION}

In dealing with a transition date, it is important to evaluate all available data, the model must be based on only short-lived samples, and a rigorous method must be deployed regarding outliers. Bayesian Model I presented in this work, as well as the other 11 published Bayesian models for the Iron I/IIA transition that used only short-lived samples, reached a date in the second half of the 10th century - in line with the Low Chronology for the Iron Age strata in the Levant. All 12 models assume a short-term transition event between the Iron I and the Iron IIA. Our Model II supposes a gradual deterioration of the late Iron I material culture rather than a sharp end. Model II also puts the Iron I/IIA transition in the second half of the 10th century BCE.

\section{ADDENDUM}

After this work was submitted for publication, we became aware of the fact that seeds from Tel Hadar have been tested in the course of the 5th International Radiocarbon Intercomparison (VIRI Scott et al. 2007: Sample D). They provided a more accurate uncalibrated date for the destruction there $(2836 \pm 3.31 \sigma)$, which puts Tel Hadar close to the earlier destruction wave-in the western Jezreel Valley. This still leaves the end of the late Iron I as a process rather than an event, but it blurs the separation between east and west.

\section{ACKNOWLEDGMENTS}

This study was prepared with the aid of the Chaim Katzman Archaeology Fund, Tel Aviv University. We wish to thank Christopher Bronk Ramsey for providing us with the OxCal specifications for the Bayesian models in Mazar and Bronk Ramsey (2008). We also wish to thank Mr Michael Cordonsky of the School of Physics at Tel Aviv University for his assistance with running our own Bayesian model.

\section{REFERENCES}

Arie E. 2006. The Iron Age I pottery: Levels K-5 and K-

4 and an intra-site spatial analysis of the pottery from

Stratum VIA. In: Finkelstein I, Ussishkin D, Halpern
B, editors. Megiddo IV: The 1998-2002 Seasons. Tel Aviv: Tel Aviv University. p 191-298.

Beck P, Kochavi M. 1985. A dated assemblage of the late 
13th century B.C.E. from the Egyptian residency at Aphek. Tel Aviv 12:29-42.

Boaretto E, Jull AJT, Gilboa A, Sharon I. 2005. Dating the Iron I/II transition in Israel: first intercomparison results. Radiocarbon 47(1):39-55.

Boaretto E, Finkelstein I, Shahack-Gross R. 2010. Radiocarbon results from the Iron IIA site of Atar Haroa in the Negev Highlands and their archaeological and historical implications. Radiocarbon 52(1):1-12.

Bronk Ramsey C. 1995. Radiocarbon calibration and analysis of stratigraphy: the OxCal program. Radiocarbon 37(2):425-30.

Bronk Ramsey C. 2001. Development of the radiocarbon calibration program. Radiocarbon 43(2A):355-63.

Cahill JM. 2006. The excavations at Tell el-Hammah: a prelude to Amihai Mazar's Beth-Shean Valley Regional Project. In: Maeir AM, de Miroschedji P, editors. I Will Speak the Riddles of Ancient Times": Archaeological and Historical Studies in Honor of Amihai Mazar. Winona Lake: Eisenbrauns. p 429-59.

Carmi I, Ussishkin D. 2004. ${ }^{14} \mathrm{C}$ dates. In: Ussishkin D. The Renewed Archaeological Excavations at Lachish (1973-1994), Volume V. Tel Aviv: Institute of Archaeology. p 2508-13.

Finkelstein I. 1988. The Archaeology of the Israelite Settlement. Jerusalem: Israel Exploration Society.

Finkelstein I. 1996. The archaeology of the United Monarchy: an alternative view. Levant 28:177-87.

Finkelstein I, Piasetzky E. 2003. Recent radiocarbon results and King Solomon. Antiquity 77(298):771-9.

Finkelstein I, Piasetzky E. $2006 .{ }^{14} \mathrm{C}$ and the Iron Age chronology debate: Rehov, Khirbet en-Nahas, Dan, and Megiddo. Radiocarbon 48(3):373-86.

Finkelstein I, Piasetzky E. 2007a. Radiocarbon and Philistine chronology. Egypt and the Levant 17:74-82.

Finkelstein I, Piasetzky E. 2007b. Radiocarbon dating and the Late-Iron I in northern Canaan: a new proposal. Ugarit-Forschungen 39:247-60.

Gadot Y. 2003. Continuity and change: cultural processes in the Late Bronze and Early Iron Ages in Israel's central coastal plain [PhD dissertation]. Tel Aviv University.

Gadot Y, Martin M, Blockman N, Arie E. 2006. Area K (Levels K-5 and K-4, the 1998-2002 seasons). In: Finkelstein I, Ussishkin D, Halpern B, editors. Megiddo IV: The 1998-2002 Seasons. Tel Aviv: Tel Aviv University. p 87-103.

Gilboa A, Sharon I. 2003. An archaeological contribution to the Early Iron Age chronological debate: alternative chronologies for Phoenicia and their effects on the Levant, Cyprus, and Greece. Bulletin of the American Schools of Oriental Research 332:7-80.

Herzog Z, Singer-Avitz L. 2004. Redefining the centre: the emergence of state in Judah. Tel Aviv 31:209-44.

Herzog Z, Singer-Avitz L. 2006. Sub-dividing the Iron IIA in northern Israel: a suggested solution to the chronological debate. Tel Aviv 33:163-95.

Humbert J-B. 1980. Les fouilles: objectifs, méthode, stratigraphie. In: Briend J, Humbert J-B, editors. Tell
Keisan (1971-1976): une cité phénicienne en Galilée. Paris: Orbis Biblicus et Orientalis. p 13-29.

Kochavi M. 1998. The eleventh century BCE tripartite pillar building at Tel Hadar. In: Gitin S, Mazar A, Stern E, editors. Mediterranean Peoples in Transition. Jerusalem: Israel Exploration Society. p 468-78.

Mazar A. 1980. Excavations at Tell Qasile Part One, The Philistine Sanctuary: Architecture and Cult Objects (Qedem 12). Jerusalem: Israel Exploration Society.

Mazar A. 1981. Giloh: an early Israelite settlement site near Jerusalem. Israel Exploration Journal 31:1-36.

Mazar A. 1985. Excavations at Tell Qasile Part Two, The Philistine Sanctuary: Various Finds, The Pottery, Conclusions, Appendixes (Qedem 20). Jerusalem: Israel Exploration Society.

Mazar A. 2005. The debate over the chronology of the Iron Age in the Southern Levant: its history, the current situation, and a suggested resolution. In: Levy TE, Higham T, editors. The Bible and Radiocarbon Dating: Archaeology, Text and Science. London: Equinox. p 15-30.

Mazar A, Bronk Ramsey C. $2008 .{ }^{14} \mathrm{C}$ dates and the Iron Age chronology of Israel: a response. Radiocarbon 50(2):159-80.

Mazar A, Bruins HJ, Panitz-Cohen N, van der Plicht J. 2005. Ladder of time at Tel Rehov: stratigraphy, archaeological context, pottery and radiocarbon dates. In: Levy TE, Higham T, editors. The Bible and Radiocarbon Dating: Archaeology, Text and Science. London: Equinox. p 193-255.

Mazar A, Panitz-Cohen N. 2001. Timnah (Tel Batash) II: The Finds from the First Millennium BCE, Text (Qedem 42). Jerusalem: Israel Exploration Society.

Schiffer MB. 1986. Radiocarbon dating and the "old wood" problem: the case of the Hohokam chronology. Journal of Archaeological Science 13(1):13-30.

Scott EM, Cook GT, Naysmith P, Bryant C, O’Donnell D. 2007. A report on Phase 1 of the 5th International Radiocarbon Intercomparison (VIRI). Radiocarbon 49(2):409-26.

Shahack-Gross R, Finkelstein I. 2008. Subsistence practices in an arid environment: a geoarchaeological investigation in an Iron Age site, the Negev Highlands, Israel. Journal of Archaeological Science 35(4):965-82.

Sharon I. 2001. 'Transition dating' - a heuristic mathematical approach to the collation of radiocarbon dates from stratified sequences. Radiocarbon 43(2A):345-54.

Sharon I, Gilboa A, Jull AJT, Boaretto E. 2007. Report on the first stage of the Iron Age Dating Project in Israel: supporting a Low Chronology. Radiocarbon 49(1): 146.

Zarzecki-Peleg A. 2005. Stratigraphy and architecture. In: Ben-Tor A, Zarzecki-Peleg A, Cohen-Anidjar S. Yoqne'am II: The Iron Age and the Persian Period. Jerusalem: Israel Exploration Society. p 5-232.

Zimhoni O. 1997. Studies in the Iron Age Pottery of Israel: Typological, Archaeological and Chronological Aspects. Tel Aviv: Institute of Archaeology. 